\title{
Determination of nitrite in tap waters based on fluorosurfactant-capped gold nanoparticles-enhanced chemiluminescence from carbonate and peroxynitrous acid
}

\author{
Jinge $\mathrm{Li},{ }^{a}$ Qianqian $\mathrm{Li}^{a}{ }^{a}$ Chao $\mathrm{Lu}^{* a}$ and Lixia $\mathrm{Zhao}^{b}$ \\ Received 16th November 2010, Accepted 16th March 2011 \\ DOI: 10.1039/c0an00918k
}

Fluorosurfactant (FSN)-capped gold nanoparticles (GNPs), which exhibit higher stability at a wider $\mathrm{pH}$ range and high ionic strength, were utilized for investigating the chemiluminescence (CL) effect on the reaction between high concentration carbonate $(\sim 0.3 \mathrm{M})$ and peroxynitrous acid. When the $\mathrm{pH}$ of the colloidal solution was 10.2 by dropwise addition of $0.05 \mathrm{M} \mathrm{NaOH}$, FSN-capped GNPs offer an enhanced CL intensity. Based on the CL spectra, XPS spectra and the quenching effect of reactive oxygen species, a possible CL mechanism is proposed. The tolerance of FSN-capped GNPs towards salt concentrations (salt proofing effect) within a large $\mathrm{pH}$ range is an interesting feature, compared to the other previously reported work on nanoparticles CL systems. The CL intensity is proportional to the concentration of nitrite in the range from 0.1 to $100 \mu \mathrm{M}$. The detection limit $(\mathrm{S} / \mathrm{N}=3)$ is $0.036 \mu \mathrm{M}$ and the relative standard deviation (RSD) for seven repeated measurements of $0.5 \mu \mathrm{M}$ nitrite was $2.4 \%$. This method has been successfully applied to determine nitrite in tap waters with recoveries of 97 $106 \%$.

\section{Introduction}

Metal nanoparticles have attracted considerable attention in the past several decades because of their inherent physical properties, such as large surface areas, good adsorption characteristics and high activity. They are extensively used in catalysis, chemical sensing, biolabeling and photonics. ${ }^{1-4}$ Recently, metal nanoparticles in chemiluminescence $(\mathrm{CL})$ reactions have been under intense investigation. In these CL systems, metal nanoparticles can participate in CL reactions as a catalyst, reductant, luminophore or energy accepter. ${ }^{5-7}$ Gold nanoparticles (GNPs), as a class of nanomaterials with many unique properties such as colorimetric, conductivity, and non-linear optical properties, have been explored within the various CL systems. ${ }^{8-11}$ For example, GNPs were found to catalyze some CL systems, such as the luminol- $\mathrm{H}_{2} \mathrm{O}_{2}$ system, ${ }^{8,9}$ bis(2,4,6-trichlorophenyl) oxalate$\mathrm{H}_{2} \mathrm{O}_{2}$ system, ${ }^{10}$ and $\mathrm{KIO}_{4}-\mathrm{NaOH}-\mathrm{Na}_{2} \mathrm{CO}_{3}$ system. ${ }^{11}$ However, all the reported GNPs-triggered $\mathrm{CL}$ systems ignored the involvement of nanoparticle conglomeration induced by high ionic strength and $\mathrm{pH}$ effect., ${ }^{711}$

In order to prevent the aggregation of GNPs, the modification of GNPs' properties by adsorbed surfactants is of greater

${ }^{a}$ State Key Laboratory of Chemical Resource Engineering, Beijing University of Chemical Technology, Beijing 100029, China. E-mail: luchao@mail.buct.edu.cn; Fax: +86 10-6441-1832; Tel: +86 10-6441-1832 ${ }^{b}$ State Key Laboratory of Environmental Chemistry and Ecotoxicology, Research Center for Eco-Environmental Sciences, Chinese Academy of Sciences, Beijing 100085, China interest, and it can make GNPs exhibit high stability in high salt solution. ${ }^{12}$ In contrast, GNPs electrostatically stabilized by adsorbed citrate ions are sensitive to the increase of salt concentration. In our previous work, GNPs capped with nonionic fluorosurfactant (FSN) molecules were reported to exhibit excellent stability in the presence of high salt concentrations and a wide $\mathrm{pH}$ range. ${ }^{13,14} \mathrm{In}$ this study, FSN-capped $14 \mathrm{~nm}$ GNPs are used for investigating the carbonate- $\mathrm{ONOOH}$ system at high salt condition ( $0.3 \mathrm{M} \mathrm{Na}_{2} \mathrm{CO}_{3}$ ). Surprisingly, when the $\mathrm{pH}$ of the colloidal solution approached 10.2 adjusted with dropwise addition of $0.05 \mathrm{M} \mathrm{NaOH}$, we found that FSN-capped GNPs exhibit an enhanced CL intensity (500-fold) between carbonate and $\mathrm{ONOOH}$. The $\mathrm{CL}$ enhancement mechanism was investigated by XPS spectra, CL spectra and the quenchers for reactive oxygen species. The idea of an amplified catalytic CL system is important in order to understand the spontaneous CL generation and carbonate-enhanced $\mathrm{ONOOH} / \mathrm{ONOO}^{-}$mechanisms.

Nitrite is an inorganic and toxic pollutant. The fatal dose of nitrite ingestion, as reported by World Health Organisation, is between 8.7 and $28.3 \mu \mathrm{M} .{ }^{15}$ Nitrite in water can react with secondary amines to form carcinogenic $N$-nitrosamines, ${ }^{16}$ and thus the nitrite content could be used as an important indicator for water pollution. For its measurement, many analytical methods have been reported, such as spectrophotometric, ${ }^{17}$ electrochemical, ${ }^{18}$ fluorometric ${ }^{19}$ and $\mathrm{CL}^{20,21}$ methods.

In the present study, we found that the CL intensity is proportional to the concentration of nitrite in the range from 0.1 to $100 \mu \mathrm{M}$. This method can be used to detect trace amounts of 
nitrite in tap waters with acceptable selectivity and reproducibility. This work is an example of the successful analytical application of nanopaticles-enhanced CL.

\section{Experimental}

\section{Materials}

All reagents were of analytical grade and used without further purification. Zonyl FSN-100 $\left(\mathrm{F}\left(\mathrm{CF}_{2} \mathrm{CF}_{2}\right)_{1-7} \mathrm{CH}_{2} \mathrm{CH}_{2} \mathrm{O}\right.$ $\left.\left(\mathrm{CH}_{2} \mathrm{CH}_{2} \mathrm{O}\right)_{0-15} \mathrm{H}\right)$ was purchased from Sigma-Aldrich. Hydrogen tetrachloroaurate(III) trihydrate $\left(\mathrm{HAuCl}_{4} \cdot 3 \mathrm{H}_{2} \mathrm{O}\right)$ was from Acros and trisodium citrate was from Tianjin Chemical Reagent Company. All solutions were prepared with ultrapure water. A $0.1 \mathrm{M}$ nitrite stock solution was prepared by $0.69 \mathrm{~g}$ $\mathrm{NaNO}_{2}$ (Tianjin Chemical Reagent Company) in $100 \mathrm{~mL}$ of water. The working solutions of nitrite were freshly prepared by diluting the nitrite stock solution with water. $0.01 \mathrm{M} \mathrm{H}_{2} \mathrm{O}_{2}$ and $0.04 \mathrm{M} \mathrm{HCl}$ were freshly prepared by volumetric dilution of commercial 30\% (v/v) $\mathrm{H}_{2} \mathrm{O}_{2}$ (Beijing Chemical Reagent Company) and 36\% (v/v) $\mathrm{HCl}$ (Beijing Chemical Reagent Company) with ultrapure water, respectively. A $0.3 \mathrm{M} \mathrm{Na}_{2} \mathrm{CO}_{3}$ working solution was prepared by dissolving appropriate amounts of $\mathrm{Na}_{2} \mathrm{CO}_{3}$ (Beijing Chemical Reagent Company) in ultrapure water. The $\mathrm{pH}$ of FSN-capped GNPs was adjusted with $0.05 \mathrm{M} \mathrm{NaOH}$ (Beijing Chemical Reagent Company).

\section{Fabrication of FSN-capped GNPs}

All glassware used for the preparation of GNPs was thoroughly washed with freshly prepared aqua regia $\left(\mathrm{HNO}_{3}: \mathrm{HCl}\right)$, rinsed extensively with ultrapure water, and then dried in an oven at $100{ }^{\circ} \mathrm{C}$ for $2-3 \mathrm{~h}$. The colloidal GNPs with average diameters of $14 \mathrm{~nm}$ were prepared by following the literature procedure. ${ }^{13}$ Briefly, a $50 \mathrm{~mL}$ solution of $0.04 \%$ trisodium citrate was brought to a vigorous boil with stirring in a round-bottom flask fitted with a reflux condenser, and then $85 \mu \mathrm{L}$ of $5 \% \mathrm{HAuCl}_{4}$ was added to the stirring and refluxing trisodium citrate solution. The solution was maintained at the boiling point with continuous stirring for $15 \mathrm{~min}$. The solution was allowed to cool at room temperature with constant stirring, and then $2 \mathrm{~mL}$ of $1 \%$ FSN100 was added into the GNPs solution. For purification of FSNcapped GNPs, the excess of reactants was removed via dialysis using a MEMBRA-CEL (MD34-7, molecular weight cutoff 7000) for 2 days in water. The suspension was stored at $4{ }^{\circ} \mathrm{C}$ until further use. The size and shape of the synthesized GNPs were characterized by transmission electron microscope (TEM) experiments. The TEM specimens were prepared by depositing an appropriate amount of GNPs onto the carbon-coated copper grids, and excess solution was wicked away by a filter paper. The grid was subsequently dried in air.

\section{Preparation of solution for $\mathrm{CL}$ detection}

The $\mathrm{pH}$ of FSN-capped GNPs colloidal solution was adjusted to 10.2 by dropwise addition of $0.05 \mathrm{M} \mathrm{NaOH}$. Afterwards the solution was kept at room temperature for about $30 \mathrm{~min} .0 .3 \mathrm{M}$ $\mathrm{Na}_{2} \mathrm{CO}_{3}$ was then added. The solution was used for CL detection immediately.

\section{Apparatus}

A Thermo Electron Nexus 8700 FT-IR spectrometer (Madison, WI, USA) was used to record FSN-capped GNPs spectra. The size and distribution of GNPs were confirmed through TEM measurements using a HITACHI-800 TEM from Hitachi (Tokyo, Japan). X-Ray photoelectron spectra were acquired on a model ESCALAB 250 electron spectrograph (VG, England). UV-visible spectra were measured on a USB 4000 miniature fiber optic spectrometer in absorbance mode with a DH-2000 deuterium and tungsten halogen light source (Ocean Optics, Dunedin, FL). The CL detection was conducted on a BPCL luminescence analyzer (Institute of Biophysics, Chinese Academy of Science, Beijing, China). The CL spectra of this system were measured with high-energy cutoff filters from 400 to $640 \mathrm{~nm}$ between the flow CL cell and the PMT.

\section{Procedures for $\mathrm{CL}$ detection}

A diagram of the flow system is shown in Fig. 1. The mixed solution of FSN-capped GNPs ( $\mathrm{pH} 10.2$ ) and $0.3 \mathrm{M} \mathrm{Na}_{2} \mathrm{CO}_{3}$ was injected into the carrier stream (water, $2.5 \mathrm{~mL} \mathrm{~min}^{-1}$ ) through a valve injector with a $120 \mu \mathrm{L}$ sample loop, and mixed with $\mathrm{ONOOH}$ through a three-way connector. ONOOH was produced on-line by the reaction between nitrite $(0.001 \mathrm{M})$ and acidified $\mathrm{H}_{2} \mathrm{O}_{2}(0.01 \mathrm{M})$. The solutions of nitrite and $\mathrm{HCl} / \mathrm{H}_{2} \mathrm{O}_{2}$ were pumped by the peristaltic pump at a rate of $2.8 \mathrm{~mL} \mathrm{~min}{ }^{-1}$. The signal output from the CL reaction was detected by the PMT.

\section{Results and discussion}

\section{Advantages of FSN-capped GNPs on CL}

In the absence of GNPs, we have compared the intensity of CL resulting from reaction between carbonate and $\mathrm{ONOOH}$ with and without FSN ligands. The results showed that in the presence of FSN ligands, the CL intensity increases $c a$. 2.5-fold (Fig. 2a). This is presumably due to the fact that the local microenvironment in micelle media is significantly different from the homogeneous media, resulting in the enhancement of CL intensity. ${ }^{21}$ When non-functionalized $14 \mathrm{~nm}$ GNPs were used in $0.3 \mathrm{M} \mathrm{Na} \mathrm{CO}_{3}$, the gold colloidal solution's color rapidly changed to blue due to its immediate aggregation, and GNPs led

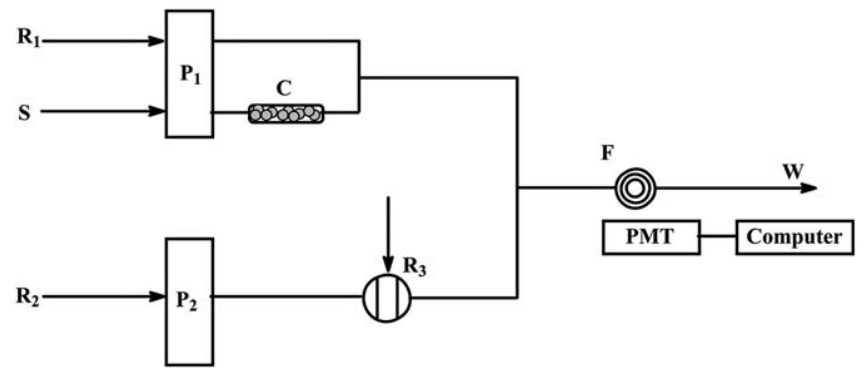

Fig. 1 Schematic diagram of the flow injection CL detection system. $\mathrm{R}_{1}$, $0.01 \mathrm{M} \mathrm{H}_{2} \mathrm{O}_{2}-0.04 \mathrm{M} \mathrm{HCl}$ at $2.8 \mathrm{~mL} \mathrm{~min}^{-1}$; $\mathrm{S}$, samples at $2.8 \mathrm{~mL} \mathrm{~min}^{-1}$; $\mathrm{R}_{2}$, carrier (water) at $2.5 \mathrm{~mL} \mathrm{~min}{ }^{-1} ; \mathrm{P}_{1}$ and $\mathrm{P}_{2}$, peristaltic pump; $\mathrm{C}, 3.0$ $\mathrm{mm}$ i.d. $\times 15.0 \mathrm{~cm}$ length column packed with 732 \# cation-exchange resin; $\mathrm{R}_{3}, 120 \mu \mathrm{L}$ FSN-capped colloid solution with $\mathrm{pH} 10.2$ in $0.3 \mathrm{M}$ $\mathrm{Na}_{2} \mathrm{CO}_{3}$; F, flow cell; PMT, photomultiplier tube $(-1000 \mathrm{~V})$; W, waste. 

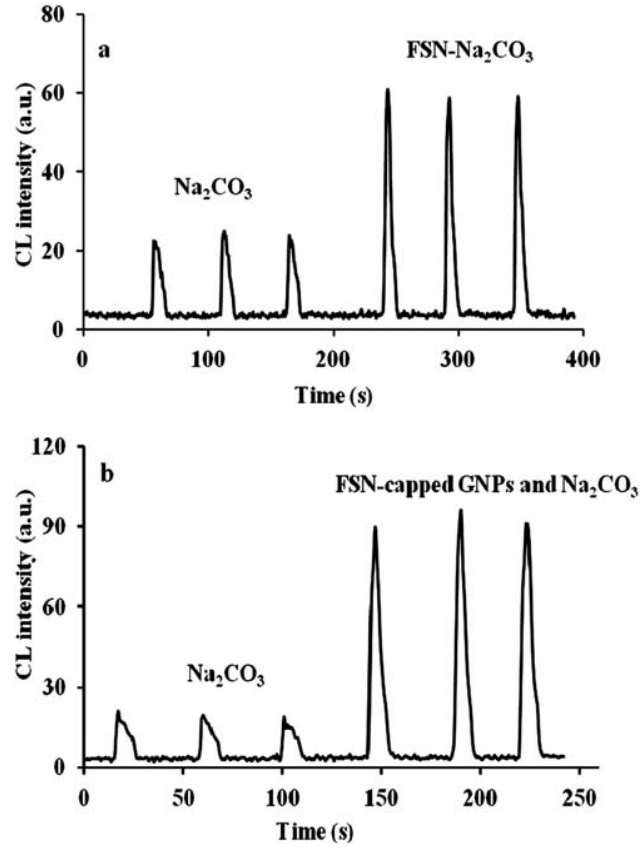

Fig. 2 (a) CL intensity of sodium carbonate in the presence and absence of $0.04 \% \mathrm{FSN}$; (b) The CL intensity with and without $0.04 \% \mathrm{FSN}$-capped $14 \mathrm{~nm}$ GNPs. Conditions: $0.01 \mathrm{M} \mathrm{H}_{2} \mathrm{O}_{2} ; 0.04 \mathrm{M} \mathrm{HCl} ; 0.001 \mathrm{M} \mathrm{NaNO}_{2}$; $0.3 \mathrm{M} \mathrm{Na}_{2} \mathrm{CO}_{3}$.

to no change in the CL intensity. In contrast, the spectral bands of functionalized $14 \mathrm{~nm}$ GNPs with FSN remained almost unchanged upon the addition of $0.3 \mathrm{M} \mathrm{Na}_{2} \mathrm{CO}_{3}$ with a 4-fold increase in CL intensity observed (Fig. 2b). The results indicated that FSN ligands play a role in CL signal enhancement.

To verify the presence of FSN on the surface of the GNPs, we carried out FT-IR and XPS measurements. For FT-IR measurements, the solid precipitates were obtained from citratestabilized GNPs or FSN-capped GNPs could be collected after they were centrifuged for three times, respectively, and then dried under vacuum at room temperature. Fig. 3a shows the FT-IR spectra of citrate-stabilized GNPs and FSN-capped GNPs. We observed the characteristic bond appearing around $1058 \mathrm{~cm}^{-1}$ in the spectrum of the FSN-capped GNPs, which might be contributed by the $\mathrm{C}-\mathrm{O}-\mathrm{C}$ groups of the FSN molecules. ${ }^{22} \mathrm{On}$ the other hand, we obtained the same solid precipitates to use XPS measurements. As shown in Fig. 3b, the results showed the binding energy of the $1 \mathrm{~s}$ atomic orbital in the fluorine atom $(\mathrm{F} 1 \mathrm{~s})$ for FSN. Two major peaks of the F1s XPS spectrum located at $689.4 \mathrm{eV}$ and $692.1 \mathrm{eV}$ were observed, which was in a good agreement with the reported results. ${ }^{23,24}$ These results demonstrated that FSN ligands can strongly adhere to the surface of GNPs.

\section{pH-dependence of CL enhancement by FSN-capped GNPs}

When $0.3 \mathrm{M} \mathrm{Na}_{2} \mathrm{CO}_{3}$ solution was injected into $\mathrm{ONOOH}$, which was prepared online by the reaction of $0.001 \mathrm{M}$ nitrite with 0.01 $\mathrm{M}$ acidified $\mathrm{H}_{2} \mathrm{O}_{2}$, a relatively weak $\mathrm{CL}$ intensity was generated (Fig. 4a). These results are consistent with our previous study. ${ }^{25}$ A small increase in CL intensity was observed when FSN-capped $14 \mathrm{~nm}$ GNPs were mixed with $0.3 \mathrm{M} \mathrm{Na}_{2} \mathrm{CO}_{3}$ (Fig. 4b). However,
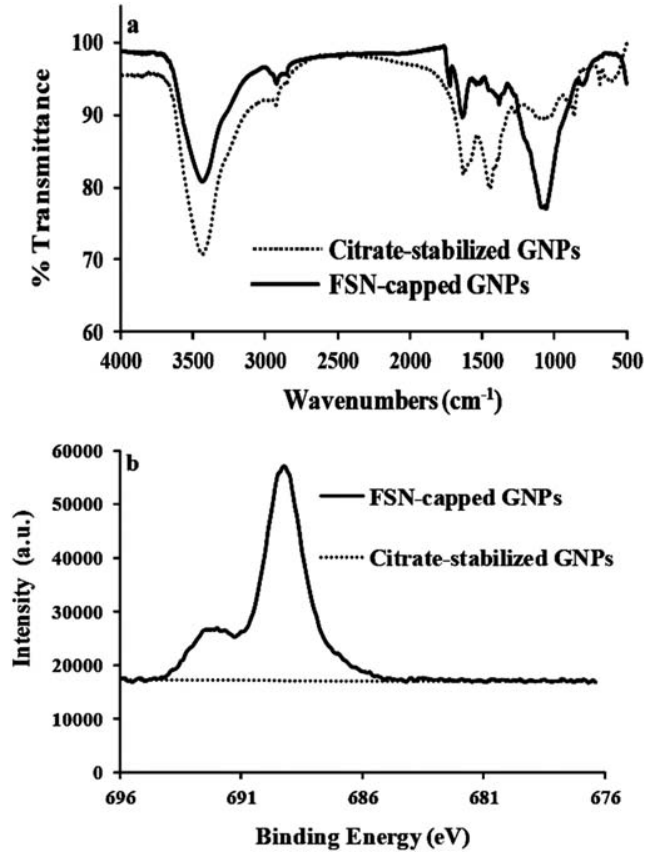

Fig. 3 (a) FT-IR spectra and (b) XPS of citrate-stabilized GNPs and FSN-capped GNPs.

if the $\mathrm{pH}$ of FSN-capped $14 \mathrm{~nm}$ GNPs colloidal solution can be adjusted to 10.2 with the dropwise addition of $0.05 \mathrm{M} \mathrm{NaOH}$ and then $0.3 \mathrm{M} \mathrm{Na}_{2} \mathrm{CO}_{3}$ was added (Fig. 4c), the CL intensity from the reaction between carbonate and $\mathrm{ONOOH}$ was increased dramatically ( $\sim 100$-fold), compared with that of not adjusting the $\mathrm{pH}$. This phenomenon is one of the most significant characteristics observed in our study. Thus we chose the final $\mathrm{pH}$ of FSN-capped GNPs as 10.2 for the excess $\mathrm{NaOH}$ resulted in the slight aggregation of GNPs.

To clarify the essence of the $\mathrm{pH}$ effect, blank experiments were carried out. The mixture of $\mathrm{Na}_{3} \mathrm{C}_{6} \mathrm{O}_{7}$ with the same concentration as the one used originally for synthesizing a solution of $14 \mathrm{~nm}$ GNPs and FSN-capped GNPs with $\mathrm{pH} 10.2$ was injected

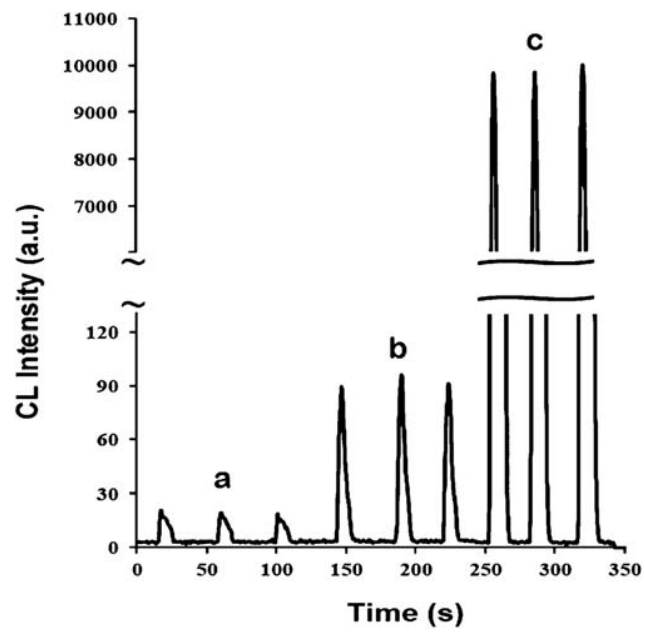

Fig. $4 \mathrm{CL}$ intensity of the FSN-capped GNPs-enhanced ONOOHcarbonate system: (a) $0.3 \mathrm{M} \mathrm{Na}_{2} \mathrm{CO}_{3}$; (b) FSN-capped GNPs (without adjusting $\mathrm{pH}$ of colloidal solution) in $0.3 \mathrm{M} \mathrm{Na}_{2} \mathrm{CO}_{3}$ solution; and (c) FSN-capped GNPs (adjusting pH to 10.2) in $0.3 \mathrm{M} \mathrm{Na}_{2} \mathrm{CO}_{3}$ solution. 


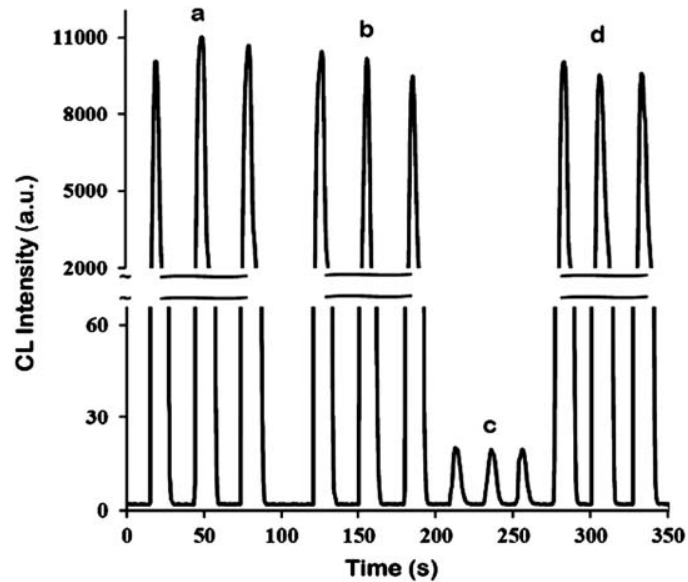

Fig. 5 CL intensity of FSN-capped GNPs-enhanced ONOOHcarbonate system under different conditions: (a) with $\mathrm{pH}$ 10.2; (b) adding $0.04 \%$ trisodium citrate in (a) solution; (c) adding $0.01 \mathrm{mM} \mathrm{HAuCl} 4$ solution in (a) solution; and (d) adding $0.01 \mathrm{mM} \mathrm{pH} 10.2 \mathrm{HAuCl}_{4}$ solution in (a) solution.

into this system. The results are shown in Fig. 5b, where no enhancement or quenching effects are found with $\mathrm{Na}_{3} \mathrm{C}_{6} \mathrm{O}_{7}$ blank solution; however, with $0.01 \mathrm{mM} \mathrm{HAuCl}$ (the concentration much lower than the one used in GNPs preparation, i.e. $0.25 \mathrm{mM} \mathrm{HAuCl}_{4}$ ) the $\mathrm{CL}$ signal quenches dramatically (Fig. 5c). When the $\mathrm{pH}$ of the $\mathrm{HAuCl}_{4}$ solution was adjusted to higher than 10.2, and then added into the FSN-capped GNPs solution $(\mathrm{pH}$ 10.2), we found that the $\mathrm{pH}$ of the solution remained constant (pH 10.2) and the CL intensity remains unchanged (Fig. 5d). It could be concluded that the formation of gold complexes from the unreacted $\mathrm{HAuCl}_{4}$ in GNPs solution or on the GNPs surface has a great effect on the CL intensity. It is well-known that there are at least four different anions present in the reaction medium during the reduction of gold(III) chloride $\left(\mathrm{AuCl}_{4}^{-}\right)$with citrate anions in aqueous solution: gold(III) chloride, citrate, chloride and hydroxide anions ${ }^{26}$ Moreover, Grieser and his co-authors reported that $\mathrm{AuCl}_{4}{ }^{-}$adsorbs on the surface of GNPs more strongly than citrate anions. ${ }^{27}$ Therefore, we speculated that when the pH of FSN-capped GNPs is 10.2, the formation of less reactive gold complexes adsorbing strongly on the surface of GNPs, such as $\left[\mathrm{AuCl}_{2}(\mathrm{OH})_{2}\right]^{-},\left[\mathrm{AuCl}(\mathrm{OH})_{3}\right]^{-}$and $\left[\mathrm{Au}(\mathrm{OH})_{4}\right]^{-}$, are displaced by citrate anions or FSN molecules from the surface of GNPs. However, these gold complexes have no effect on the present $\mathrm{CL}$ system because the $\mathrm{HAuCl}_{4}$ solution at $\mathrm{pH}$ 10.2 did not quench the CL signal (see Fig. 5d).

\section{Identification of FSN-capped GNPs after the CL reaction}

There are two possibilities for the function of FSN-capped GNPs in the $\mathrm{CL}$ reaction. One possibility is that GNPs are involved in the $\mathrm{ONOOH}$-carbonate $\mathrm{CL}$ reaction as a catalyst, and the other is that GNPs are oxidized to $\mathrm{Au}(\mathrm{I})$ or $\mathrm{Au}(\mathrm{III})$ during the $\mathrm{CL}$ reaction. Therefore, it is of vital importance to identify whether GNPs or the oxidized gold species were present in the solution after the CL reaction. XPS (Fig. 6) data showed the scanning range of binding energy of GNPs, in which a double-peak occurs at 83.7 and $87.3 \mathrm{eV}$, corresponding to $\mathrm{Au} 4 \mathrm{f}_{7 / 2}$ and $\mathrm{Au} 4 \mathrm{f}_{5 / 2}$, respectively, ${ }^{28,29}$ indicating a typical character of the presence of

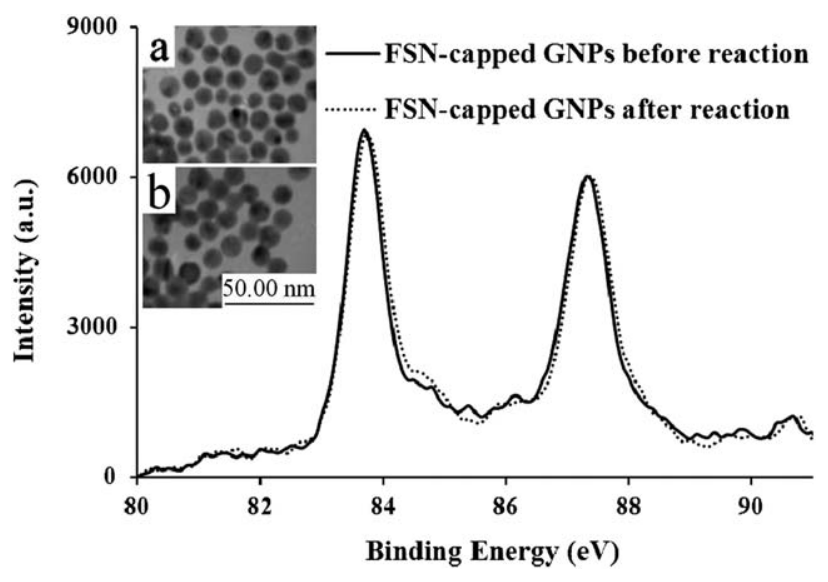

Fig. 6 XPS of FSN-capped GNPs ( $\mathrm{pH}$ 10.2)-0.3 M carbonate (a) before and (b) after the reaction with ONOOH. Inset: TEM images of FSNcapped GNPs (a) before and (b) after the reaction.

the $\mathrm{Au}^{0}$ state. The result showed that the binding energy of $\mathrm{Au} 4 \mathrm{f}$ for GNPs during the reaction process was almost the same, and these results demonstrated that the oxidation state of gold (i.e. $\mathrm{Au}(\mathrm{I})$ complex) was not generated after the $\mathrm{CL}$ reaction. Therefore, the $\mathrm{CL}$ was assigned to the catalytic effects of FSN-capped GNPs but not an Au(I) complex. ${ }^{10,11}$ Also, TEM in the inset photos in Fig. 6 revealed that the shape and size of the FSNcapped GNPs did not aggregate before or after the CL reaction.

\section{Emitting species studies}

The CL mechanism for the reaction of carbonate with online preparation of $\mathrm{ONOOH}$ has been summarized in our previous paper. ${ }^{25}$ It was deduced that the recombination and decomposition of $\mathrm{CO}_{3}{ }^{-}$radicals generated light emission, and that the emission band is approximately at $400-460 \mathrm{~nm}$. We investigated the CL spectra of the system in the presence of FSN-capped GNPs with cutoff filters of various wavelengths. There was only a peak band in the range between 430 and $450 \mathrm{~nm}$, which is in good agreement with the wavelength band from carbonate with ONOOH. However, we noted that the shoulders at higher wavelengths existed. They were probably attributed to the small amount of singlet oxygen dimol species. ${ }^{30}$ These results further confirmed that the FSN-capped GNPs act as a catalyst in the present CL system.

The emitting species from the examined system was also confirmed by the quenching effect of reactive oxygen species. 1,4Diazabicyclo[2.2.2] octane (DABCO) and $\mathrm{NaN}_{3}$, well-known quenchers of singlet oxygen $\left({ }^{1} \mathrm{O}_{2}\right),{ }^{31}$ were used in the present experiment, and the results showed that $50 \mathrm{mM}$ DABCO and 100 $\mathrm{mM} \mathrm{NaN}$ did not quench the CL intensity, which provided strong evidence that ${ }^{1} \mathrm{O}_{2}$ did not contribute to the observed $\mathrm{CL}$. However, the CL signal was effectively quenched by $0.1 \mathrm{mM}$ ascorbic acid (a quencher of hydroxyl radicals), ${ }^{32}$ which evidently supports the assumption that the hydroxyl radical was the emitter or intermediate product.

\section{Mechanism discussion}

Based on the above results, the CL mechanism can be summarized as shown in Scheme 1. The gold complexes were 
formed from the unreacted $\mathrm{HAuCl}_{4}$ in GNPs solution or on the GNPs surface by dropwise addition of $\mathrm{NaOH}$ and were displaced by FSN molecules from the surface of the GNPs. The FSN molecules are adsorbed with their hydrophilic heads on the gold surface to form the micellar layer, resulting in the improvement of the CL quantum yield. ${ }^{33}$ The generated hydroxyl radicals from the decomposition of $\mathrm{ONOOH}^{34}$ via partial electron exchange interactions between $\mathrm{OH}$ radicals and $\mathrm{CO}_{3}{ }^{2-}$, result in the production of many more $\mathrm{CO}_{3}{ }^{-}$ radicals. ${ }^{35}$ On the other hand, the special microenvironment of the FSN micelle solution minimizes the probability of collision of $\mathrm{CO}_{3}{ }^{-}$radicals with solvent molecules. ${ }^{21}$ The produced $\mathrm{CO}_{3}{ }^{-}$ radicals displace the citrate ions or FSN ligands on the surface of the GNPs and the adjacent adsorbed radicals would react to form molecular dimers as in the case of exothermic surface reactions between a molecule and a metal surface. ${ }^{11}$ Therefore, it can be deduced that the presence of GNPs greatly stimulates the generation of the excited states of the carbon dioxide dimer, which contributed to the observed CL bands of 430 $450 \mathrm{~nm}^{25}$

\section{Standard curve and detection limit}

Under the optimum experimental conditions employed in the present study, the calibration curve was found to be linear from 0.1 to $100 \mu \mathrm{M}$ for nitrite (Fig. 7), and a regression line $y=$ $75.675 x+666.13\left(R^{2}=0.9906\right)$ where $y$ is the CL intensity and $x$ is the concentration of nitrite (Fig. 7, inset). The detection limit $(\mathrm{S} / \mathrm{N}=3)$ was $0.036 \mu \mathrm{M}$ nitrite. The relative standard deviation for seven repeated measurements of $0.5 \mu \mathrm{M}$ nitrite was $2.4 \%$.

\section{Interferences}

To assess the selectivity of the developed method, the effects of typically common interferents present in tap water samples were investigated. The tolerance limit was taken as the amount which caused an error of less than $5 \%$ for the determination of $1.0 \mu \mathrm{M}$ nitrite. The results were summarized in Table 1 . The influences of most anions on the $\mathrm{CL}$ intensity were very slight, and most cations, 1000-fold $\mathrm{Na}^{+}, \mathrm{K}^{+}, \mathrm{Ca}^{2+}, \mathrm{Pb}^{2+}$ and 500-fold $\mathrm{Ba}^{2+}, \mathrm{Cd}^{2+}$, $\mathrm{Mg}^{2+}$, have no influence on the determination of $1.0 \mu \mathrm{M}$ nitrite.

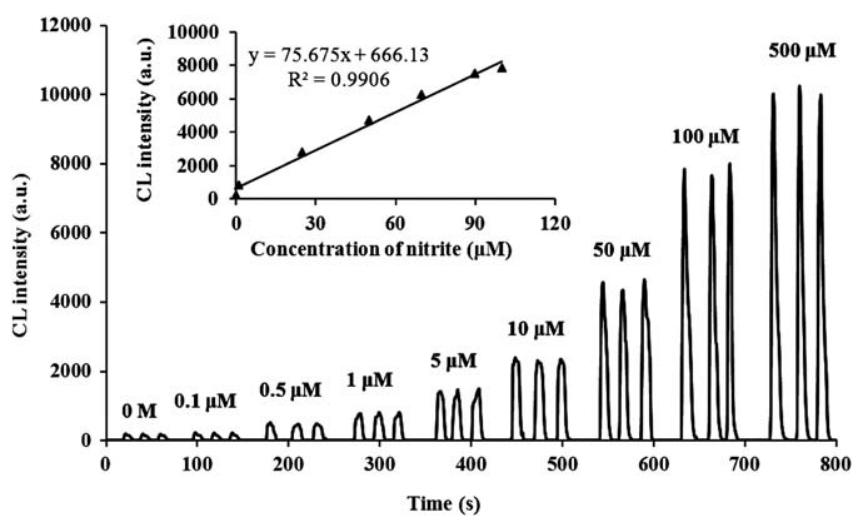

Fig. $7 \mathrm{CL}$ intensity of FSN-capped GNPs-enhanced ONOOHcarbonate by adding different concentrations of nitrite. Inset, the calibration curve for the detection of nitrite.

However, a few cations, such as $\mathrm{Co}^{2+}$ and $\mathrm{Cr}^{3+}$, interfered seriously. In order to eliminate the interferences from cations, a column (Teflon tube: $15.0 \mathrm{~cm}$ in length and $3 \mathrm{~mm}$ i.d.) of 732\# cation-exchange resin was assembled. The results showed that the interferences of these cations can be removed well with the cation-exchange column.

\section{Analysis of real samples}

The concentrations of nitrite in tap water were determined by the proposed method. One of the sources of tap water is river water, lake water and dam water, the other source is well water and ground water. In the tap water originating from well water and ground water, coexisting inorganic ions listed in Table 1 are present at high concentrations, and they interfere with the determination of nitrite. Therefore, the proposed method is applicable for tap water from river water, lake water and dam water. Freshly collected tap water samples originating from dam water were kept in a refrigerator at about $4{ }^{\circ} \mathrm{C}$ and analyzed by the recommended procedure within $4 \mathrm{~h}$ of collection. Using the standard addition method, the calibration curve in tap water was obtained and used to determine nitrite. The results in Table 2 are

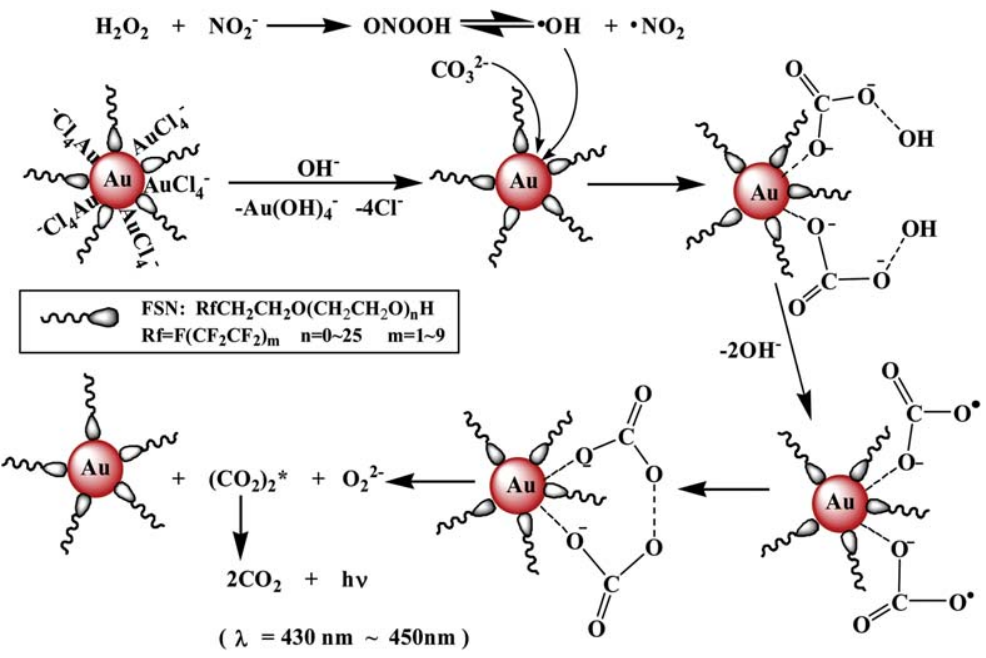

Scheme 1 Possible mechanism for ONOOH-carbonate system with FSN-capped GNPs (pH 10.2). 
Table 1 Tolerance limit of various coexistent substances on the determination of $1.0 \mu \mathrm{M}$ nitrite

\begin{tabular}{ll}
\hline Tolerance & Coexistent substances/ $\mu \mathrm{M}$ \\
\hline 1000 & $\mathrm{CO}_{3}^{2-}, \mathrm{HCO}_{3}^{-}, \mathrm{NO}_{3}^{-}, \mathrm{SO}_{4}^{2-}, \mathrm{SO}_{3}^{2-}, \mathrm{SiO}_{3}^{2-}$, \\
& $\mathrm{Cl}^{-}, \mathrm{OH}^{-}, \mathrm{F}^{-}, \mathrm{HSO}_{3}^{-}, \mathrm{Br}^{-}, \mathrm{NH}_{4}^{+}, \mathrm{PO}_{4}^{3-}$, \\
& $\mathrm{H}_{2} \mathrm{PO}_{4}^{-}, \mathrm{HPO}_{4}^{2-}, \mathrm{Na}^{+}, \mathrm{K}^{+}, \mathrm{Ca}^{2+}, \mathrm{Pb}^{2+}$ \\
500 & $\mathrm{Ba}^{2+}, \mathrm{Cd}^{2+}, \mathrm{OCl}^{-}, \mathrm{Mg}^{2+}$ \\
100 & $\mathrm{Al}^{3+}, \mathrm{Zn}^{2+}, \mathrm{Cu}^{2+}$ \\
0.1 & $\mathrm{Ni}^{2+}, \mathrm{Fe}^{2+}$ \\
0.00001 & $\mathrm{Co}^{2+}, \mathrm{Cr}^{3+}$ \\
\hline
\end{tabular}

Table 2 Determination of nitrite in tap water samples

\begin{tabular}{|c|c|c|c|c|c|}
\hline Sample $^{a}$ & $\begin{array}{l}\text { Proposed } \\
\mathrm{method} / \mu \mathrm{M}\end{array}$ & $\begin{array}{l}\text { Standard } \\
\text { method } / \mu \mathrm{M}\end{array}$ & Added $/ \mu \mathrm{M}$ & Found $/ \mu \mathrm{M}$ & $\begin{array}{l}\text { Recovery } \\
(\%)\end{array}$ \\
\hline \multirow[t]{2}{*}{ A } & \multirow[t]{2}{*}{0.11} & \multirow[t]{2}{*}{0.13} & 0.50 & 0.52 & 104 \\
\hline & & & 1.00 & 1.00 & 100 \\
\hline \multirow[t]{2}{*}{ B } & \multirow[t]{2}{*}{0.29} & \multirow[t]{2}{*}{0.23} & 0.50 & 0.48 & 96 \\
\hline & & & 1.00 & 0.98 & 98 \\
\hline \multirow[t]{2}{*}{$\mathrm{C}$} & \multirow[t]{2}{*}{0.42} & \multirow{2}{*}{0.49} & 0.50 & 0.52 & 104 \\
\hline & & & 1.00 & 0.99 & 99 \\
\hline
\end{tabular}

${ }^{a}$ Samples A-C were tap waters obtained from three different districts of Beijing: (A) Chaoyang District; (B) Haidian District; (C) Changping District.

in concordance with those obtained by a standard spectrophotometric method, ${ }^{36}$ and the recoveries for the samples were $97-$ $106 \%$.

\section{Conclusions}

In summary, we have demonstrated that FSN-capped $14 \mathrm{~nm}$ GNPs adjusted to $\mathrm{pH} 10.2$ by dropwise addition of $0.05 \mathrm{M}$ $\mathrm{NaOH}$ can significantly enhance the CL signal (500-fold) using high concentrations of carbonate and $\mathrm{ONOOH}$. The produced emitting species from the examined system was found to be the excited state of the carbon dioxide dimer, which contributes to the observed CL bands of 430-450 nm. In addition, we identified that the unreacted $\mathrm{HAuCl}_{4}$ in GNPs solution or on the GNPs surface has a great effect on the CL intensity. This work is of great importance towards understanding the origin of the emission between carbonate and ONOOH. To the best of our knowledge, this is the first work using modified GNPs to amplify the CL signal at high salt concentrations and a wide $\mathrm{pH}$ range, which exhibits its perspective in the other ultra-weak CL systems. The analytical application of the present CL system was achieved by the determination of nitrite in tap waters.

\section{Acknowledgements}

This work was financially supported by the National Natural Science Foundation of China (Nos. 20975010, 20907060 and 21077008).

\section{References}

1 G. Schneider, G. Decher, N. Nerambourg, R. Praho, M. H. V. Werts and M. Blanchard-Desce, Nano Lett., 2006, 6, 530-536.

2 N. Nath and A. Chilkoti, Anal. Chem., 2002, 74, 504-509.

3 Z. Y. Zhong, S. Patskovskyy, P. Bouvrette, J. H. T. Luong and A. Gedanken, J. Phys. Chem. B, 2004, 108, 4046-4052.

4 K. Sato, K. Hosokawa and M. Maeda, J. Am. Chem. Soc., 2003, 125, 8102-8103.

5 X. Wang, N. Na, S. C. Zhang, Y. Y. Wu and X. R. Zhang, J. Am. Chem. Soc., 2007, 129, 6062-6063.

6 N. Na, S. C. Zhang, X. Wang and X. R. Zhang, Anal. Chem., 2009, 81, 2092-2097.

7 J.-M. Lin and M. L. Liu, J. Phys. Chem. B, 2008, 112, 7850-7855.

8 S. L. Zhao, T. X. Niu, Y. R. Song and Y. M. Liu, Electrophoresis, 2009, 30, 1059-1065.

9 Z.-F. Zhang, H. Cui, C.-Z. Lai and L.-J. Liu, Anal. Chem., 2005, 77, $3324-3329$

10 H. Cui, Z.-F. Zhang, M.-J. Shi, Y. Xu and Y.-L. Wu, Anal. Chem., 2005, 77, 6402-6406.

11 H. Cui, Z.-F. Zhang and M.-J. Shi, J. Phys. Chem. B, 2005, 109, 3099 3103.

12 B. Nikoobakht and M. A. El-Sayed, Langmuir, 2001, 17, 6368-6374.

13 C. Lu, Y. B. Zu and V. W. W. Yam, Anal. Chem., 2007, 79, 666-672.

14 C. Lu and Y. B. Zu, Chem. Commun., 2007, 3871-3873.

15 M. Khairy, R. O. Kadara and C. E. Banks, Anal. Methods, 2010, 2, 851-854.

16 M. Masuda, H. F. Mower, B. Pignatelli, I. Celan, M. D. Friesen, H. Nishino and H. Ohshima, Chem. Res. Toxicol., 2000, 13, 301-308.

17 H. P. S. Rathore and S. K. Tiwari, Anal. Chim. Acta, 1991, 242, $225-$ 228.

18 J. H. Pei and X. Y. Li, Talanta, 2000, 51, 1107-1115.

19 D. W. Bedwell, V. R. Rivera, G. A. Merrill and A. E. Pusaterr, Anal. Biochem., 2000, 284, 1-5.

20 E. Nagababu and J. M. Rifkind, Free Radical Biol. Med., 2007, 42, 1146-1154.

21 C. Lu, F. Qu, J.-M. Lin and M. Yamada, Anal. Chim. Acta, 2002, 474, $107-114$.

22 Y. A. Tang, J. W. Yan, X. S. Zhou, Y. C. Fu and B. W. Mao, Langmuir, 2008, 24, 13245-13249.

23 S. J. Pan, H. C. Liang, C. Q. Wang, F. W. Yang, X. D. Li and S. Yang, Sci. China, Ser. B: Chem., 2009, 52, 2043-2046.

24 A. Devadoss and C. E. D. Chidsey, J. Am. Chem. Soc., 2007, 129, $5370-5371$.

25 C. Lu, J.-M. Lin, C. W. Huie and M. Yamada, Anal. Chim. Acta, 2004, 510, 29-34.

26 X. H. Ji, X. N. Song, J. Li, Y. B. Bai, W. S. Yang and X. G. Peng, J. Am. Chem. Soc., 2007, 129, 13939-13948.

27 S. Biggs, P. Mulvaney, C. F. Zukoski and F. Grieser, J. Am. Chem. Soc., 1994, 116, 9150-9157.

28 M. P. Casaletto, A. Longo, A. Martorana, A. Prestianni and A. M. Venezia, Surf. Interface Anal., 2006, 38, 215-218.

29 P. Jiang, S. S. Xie, J. N. Yao, S. T. He, H. X. Zhang, D. X. Shi, S. J. Pang and H. J. Gao, Chin. Sci. Bull., 2001, 46, 996-998.

30 S. C. Zhang, Y. Y. Wu and H. Li, Talanta, 2000, 53, 609-616.

31 D. V. Kazakov, V. P. Kazakov, G. Y. Maistrenko, D. V. Malzev and R. Schmidt, J. Phys. Chem. A, 2007, 111, 4267-4273.

32 T. Suzuki, T. Noro, Y. Kawamura, K. Fukunaga, M. Watanabe, M. Ohta, H. Sugiue, Y. Sato, M. Kohno and K. Hotta, J. Agric. Food Chem., 2002, 50, 633-641.

33 A. Safavi and M. A. Karimi, Anal. Chim. Acta, 2002, 468, 53-63.

34 H. Gunaydin and K. N. Houk, J. Am. Chem. Soc., 2008, 130, 1003610037.

35 E. C. Kennett and M. J. Davies, Free Radical Biol. Med., 2009, 47, 389-400.

36 F. S. Wei, Analytical Methods for the Examination of Water and Wastewater, Chinese Environment and Science Press, Beijing, 3rd edn, 1998, 260. 